\title{
Effect of Pilates for 8 Weeks on Cortisol and Lipid Profile in Obese Women
}

\author{
Hashemi A. ${ }^{1}$ MSc, Taghian F.* PhD, Kargar Fard M. ${ }^{2}$ PhD
}

*Exercise Physiology Department, Physical Education \& Sport Sciences Faculty, Khorasgan Branch, Islamic Azad University, Isfahan, Iran

${ }^{1}$ Exercise Physiology Department, Physical Education \& Sport Sciences Faculty, Khorasgan Branch, Islamic Azad University, Isfahan, Iran

2Exercise Physiology Department, Physical Education \& Sport Sciences Faculty, Isfahan University, Isfahan, Iran

\begin{abstract}
Aims: Today, obesity is one of the major health problems of human society. This study aimed to investigate the effect of 8 weeks Pilates on cortisol and lipid profile in obese women.

Materials \& Methods: This quasi-experimental study was done on 20 non-

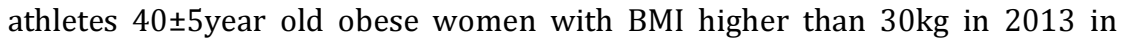
Najaf Abad; Isfahan. Samples were divided into Pilates $(n=10)$ and control group $(n=10)$. Pilates Group were performed Pilates exercises 3 times per week for 8 weeks, each session $60 \mathrm{~min}$, while control group just were followed. Lipids, including HDL, LDL, triglycerides before and $48 \mathrm{~h}$ after 8 weeks were measured. Data were analyzed by SPSS 19 and independent and correlational-T test.

Findings: 8 week Pilates significantly reduced weight $(p=0.02)$, BMI $(p=0.01)$, cholesterol $(\mathrm{p}=0.01)$, LDL $(\mathrm{p}=0.001)$ and a significant increase in cortisol in obese women in the exercise group compared with the control group.

Conclusion: Pilates, decreases weight and body mass index, cholesterol and LDL and increases cortisol.
\end{abstract}

\section{Keywords}

Exercise [http://www.ncbi.nlm.nih.gov/mesh/68015444];

Obesity [http://www.ncbi.nlm.nih.gov/mesh/68009765];

Lipids [http://www.ncbi.nlm.nih.gov/mesh/68008055];

Lipoproteins, HDL [http://www.ncbi.nlm.nih.gov/mesh/68008075]

\footnotetext{
${ }^{*}$ Corresponding Author

Tel: +983135354001

Fax: +983135354135

Address: Physical Education \& Sport Sciences Faculty, Khorasgan Branch, Islamic Azad University, Arqavanieh, Isfahan, Iran 


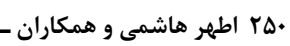

ييشسلول هاى هربى شبهفيبروبلاستى تشكيل شوند. بروز خاقى در

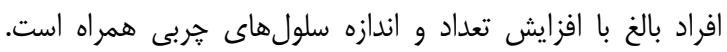
جاقى و ناهنجارىهاى ليبيدى از اصلىترين عوامل برائ بروز

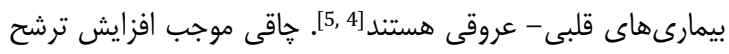

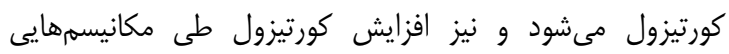

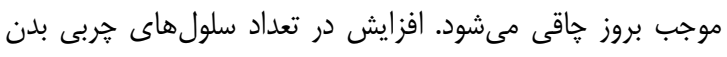

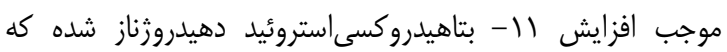

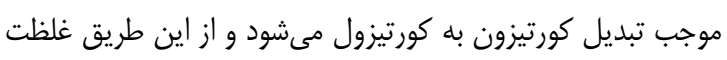

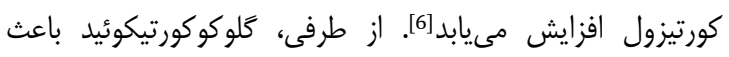

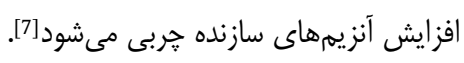

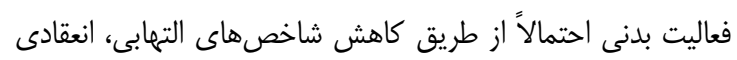

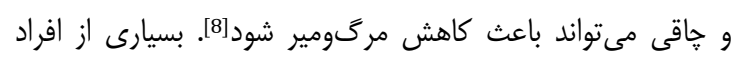

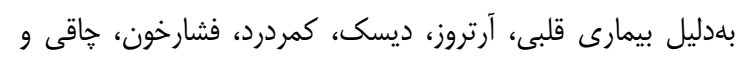

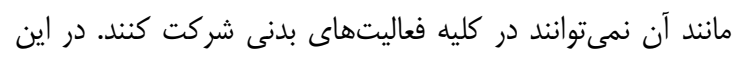

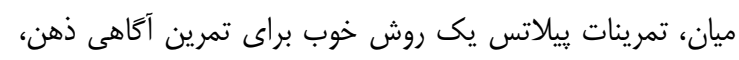

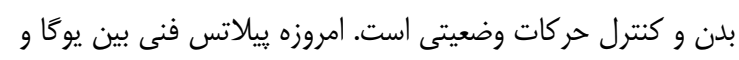

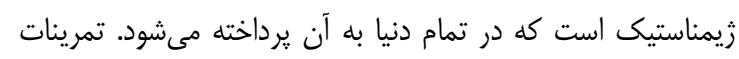

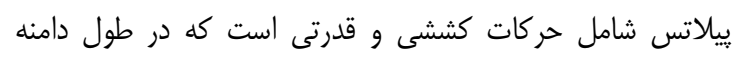

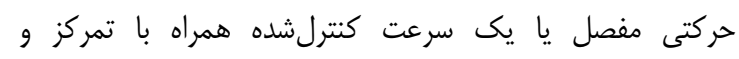

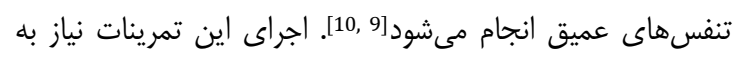

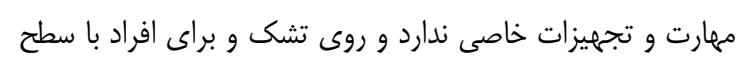

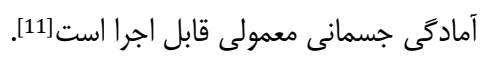

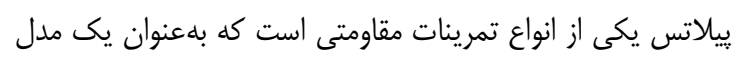

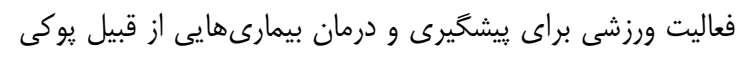

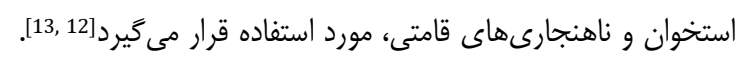

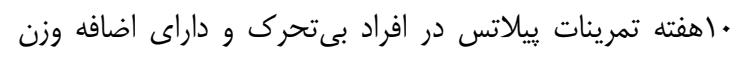

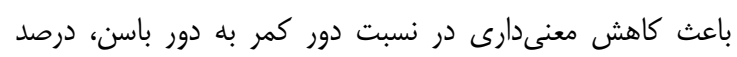

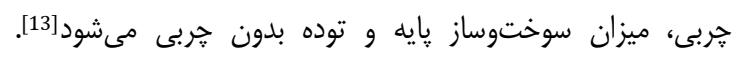

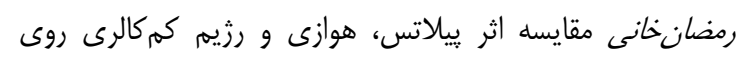

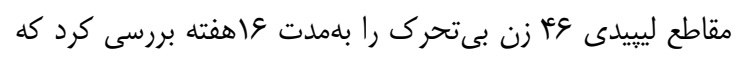

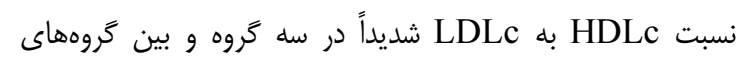

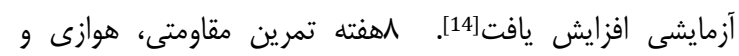

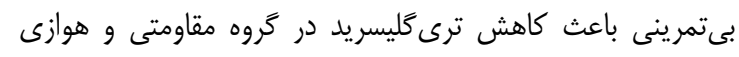

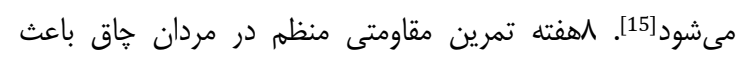

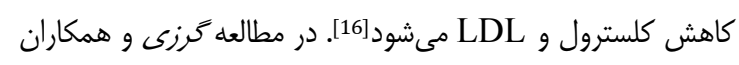

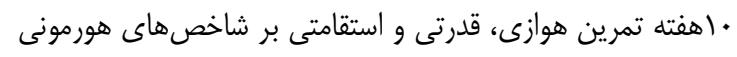

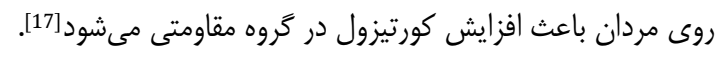

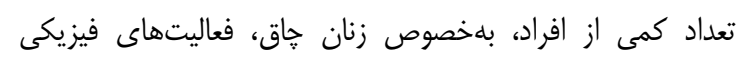

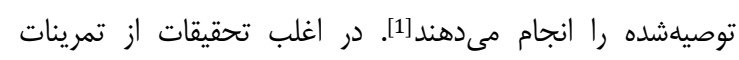

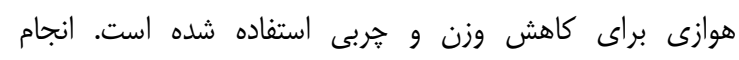

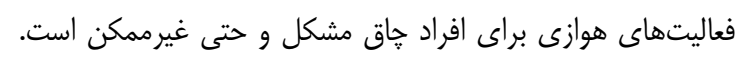
با توجه به اينكه تمرينات بيلاتس دراي افران حالتهائ وائ ايستاده، نشسته و

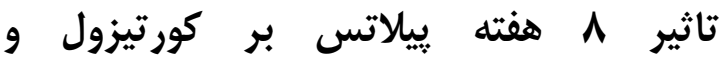 شاخصهاى جربى در زنان جاق هُش}

اطرهر هاشمى MSe كَروه فيزيولوزى ورزشى، دانشكده تربيت بدنى إنى و علوم ورزشى، واحد خوراسكان، دانشًاه آزاد اسلامى، اصفهان، ايران

فرزانه تقيان" كروه فيزيولوزى ورزشى، دانشكده تربيت بدنى و علوم ورزشى، واحد خوراسكان، إنهان

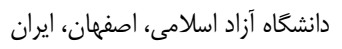

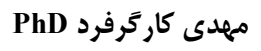
كَروه فيزيولوزى ورزشى، دانشكده تربيت بدنى و علوم ورزشى، دانشخاه اصفهان، اصفهان، ايران

جִكيده

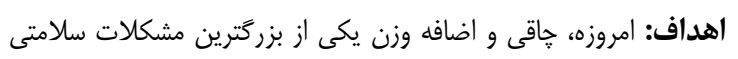

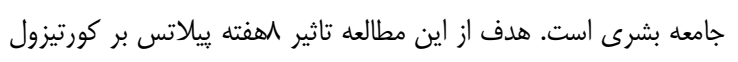
و شاخصهاى هربى در زنان هاق باق بود.

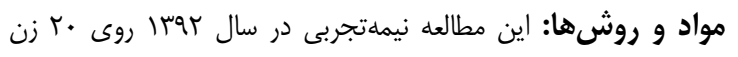

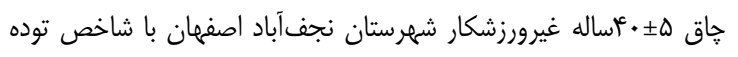

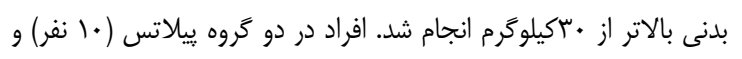

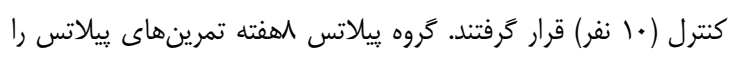

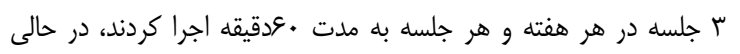

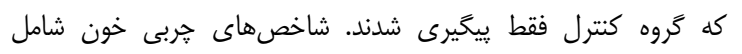

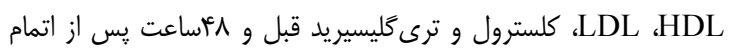

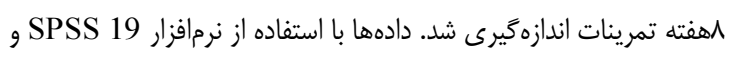

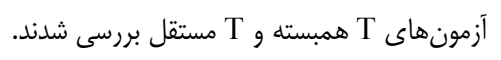

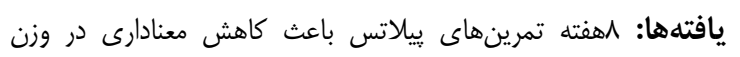

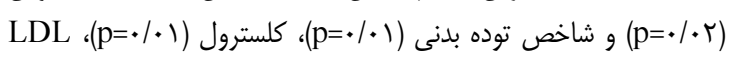

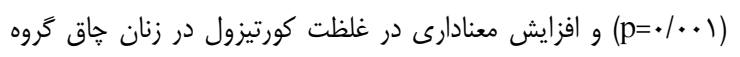
تمرين در مقايسه با كروه كنترل شداند

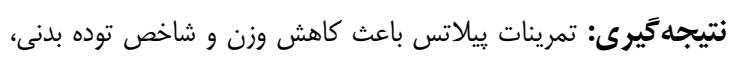

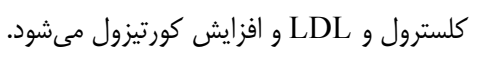
كليدوازهها: تمرين؛ هاقى؛ لييبدها؛ لييويروتئين كمهيخال

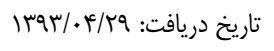

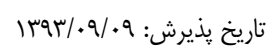
f_taghian@yahoo.com :

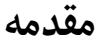

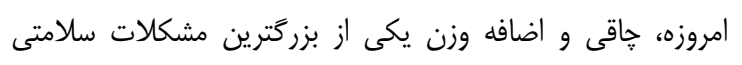

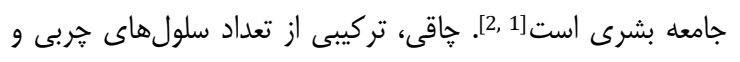

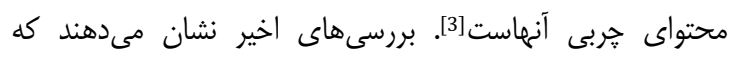

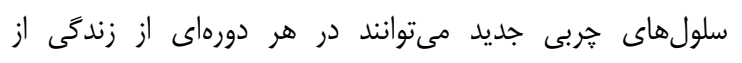

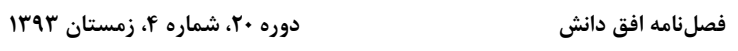




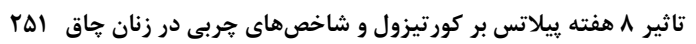

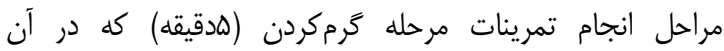

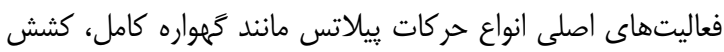

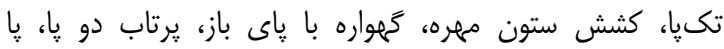

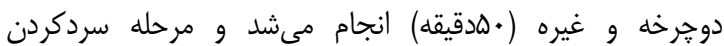

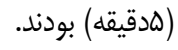

در اولين جلسه، اصول يايه تمرينات ييلاتس براى آزمودنىها

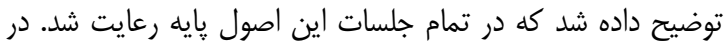

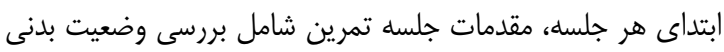

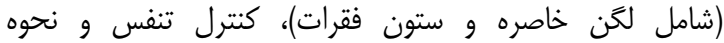

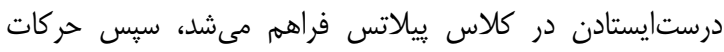

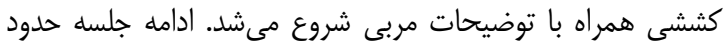

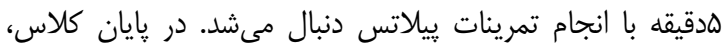

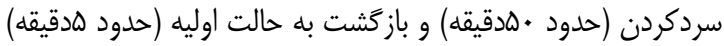

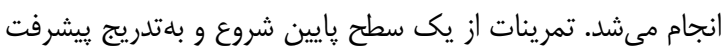

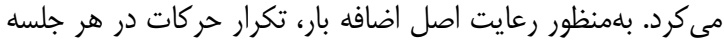

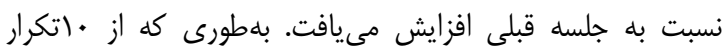

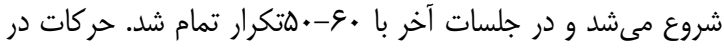

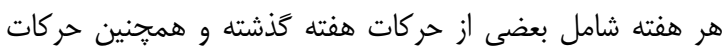

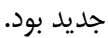
خون گيرى در دو مرحله، عآساعت قبل از شروع اولين جلسه تمرين

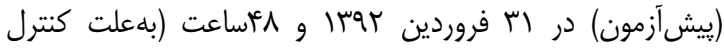

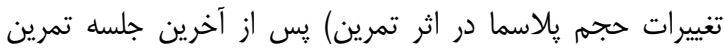

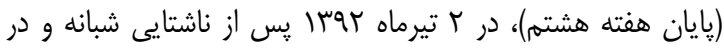

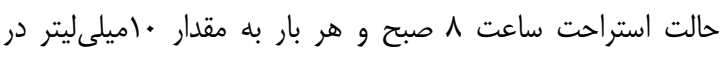

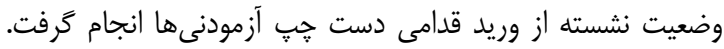

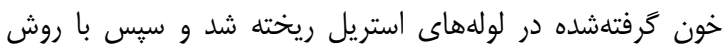
سانتريفوز (بهمدت • ادقيقه با ..."ادور در دقيقه) سرم از يلاسما

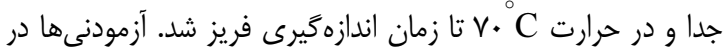

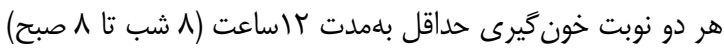

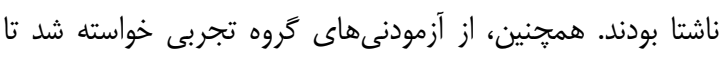

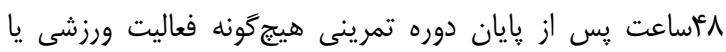

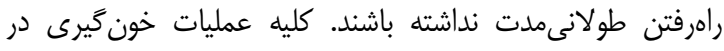

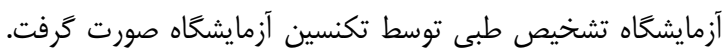

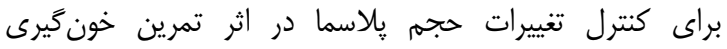

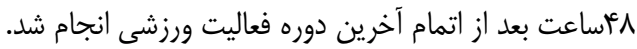

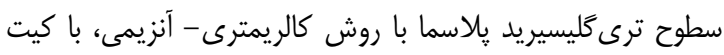

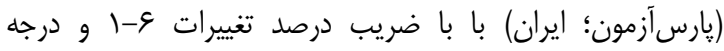

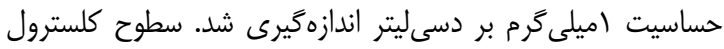

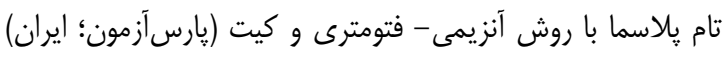

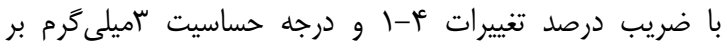

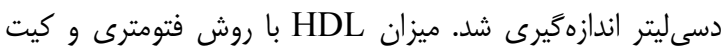

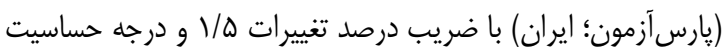

خوابيده بدون طى مسافت و يرش و جهش انجام مى گيرد،

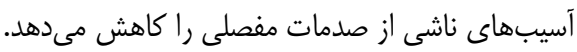

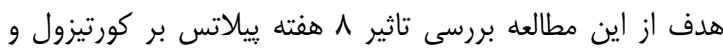
شاخصهاى جربى در زنان جاق بودان

\section{مواد و روشها}

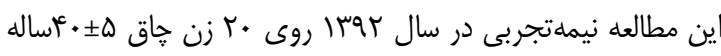

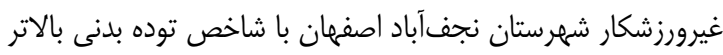

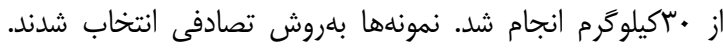

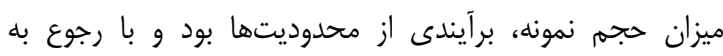

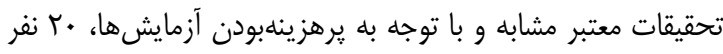

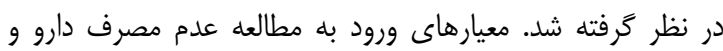

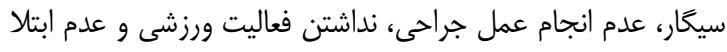

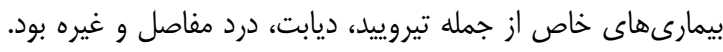

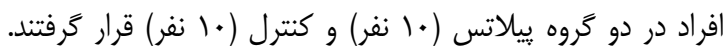

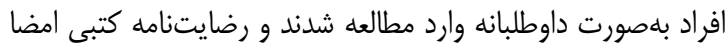
نمودند. براى كنترل برنامه غذايى آزمودنىها از يرسشنامه يادآمد عآساعته

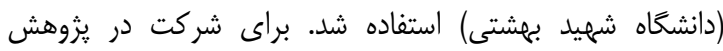

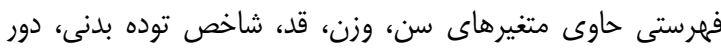

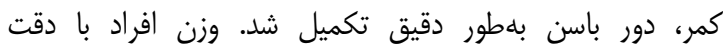

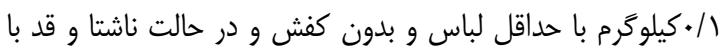

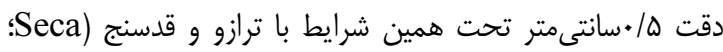

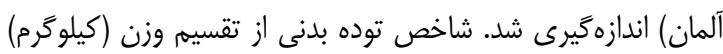
بر مجذور قد (مترمربع) محاسبه شد.

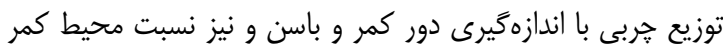

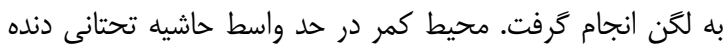

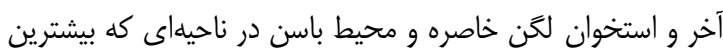

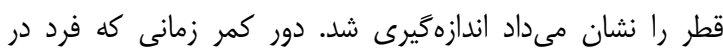
انتهاى بازدم طيبعى خود قرار داشت توسط يك متر نوارى غيرقابل

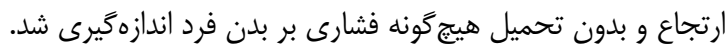

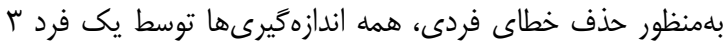

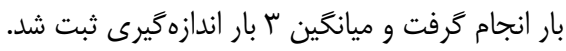

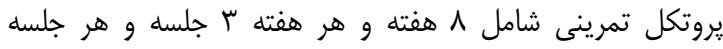

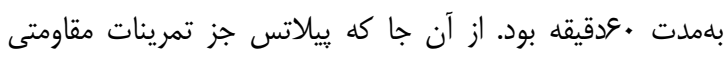

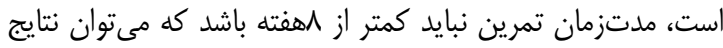

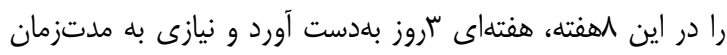

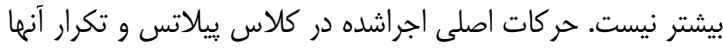

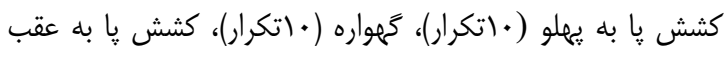

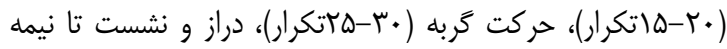

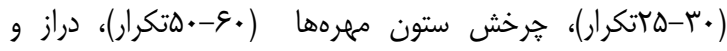

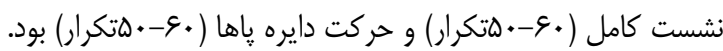




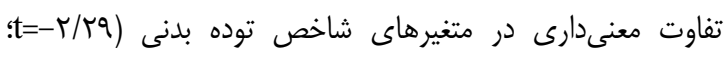

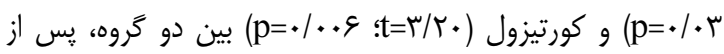

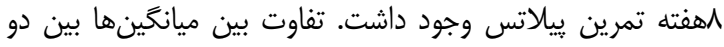

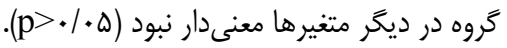

\section{بحث}

مطالعه حاضر با هدف ارزيابى تاثير لهفته تمرين بيلاتس بر

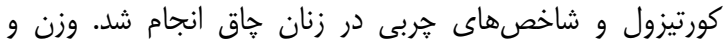

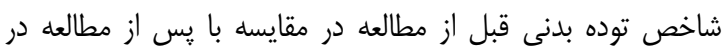

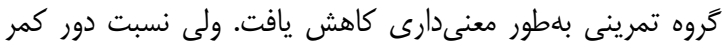

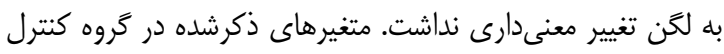

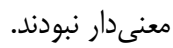
• اهفتله بيالاتس باعث كاهش معنىدار وزن و شاخص توده بدنى زنان داراى اضافه وزن مىشود كه با تحقيق ما همخوانى دارد در

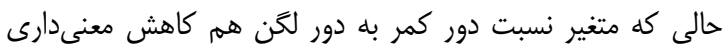
داشته است كه با مطالعه ما در مورد دور كمر همخخوانى ندارد [13].

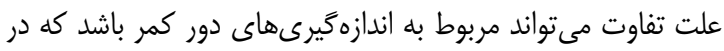

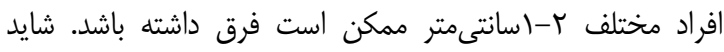

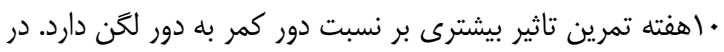

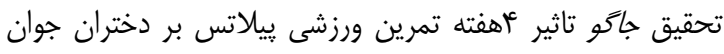

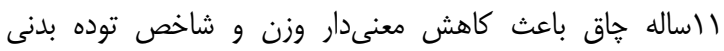

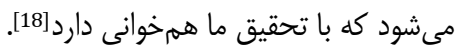

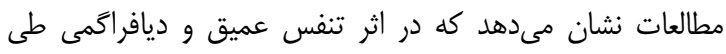

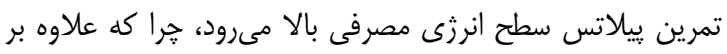

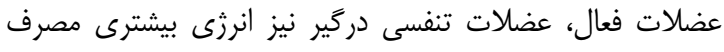

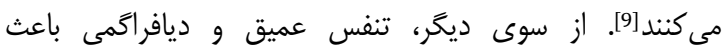

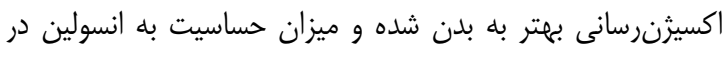

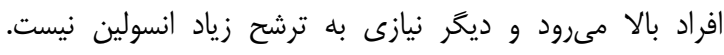

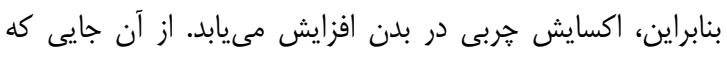

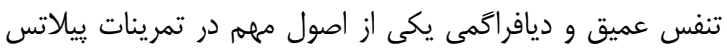

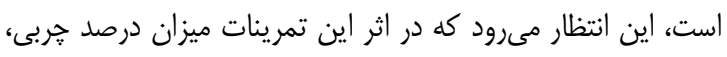

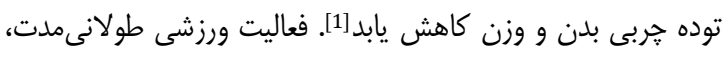

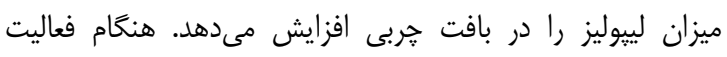

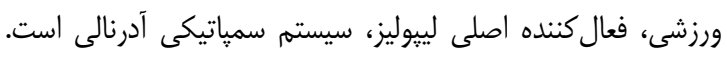

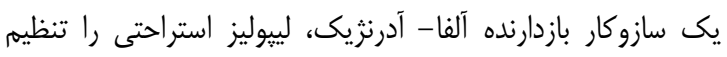

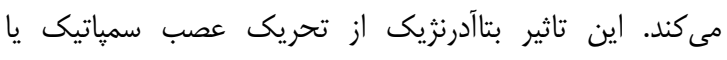

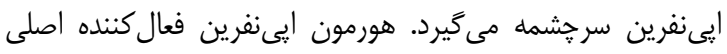

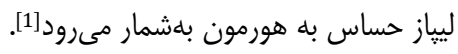

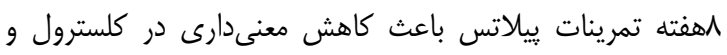

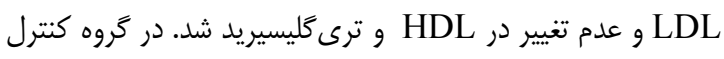

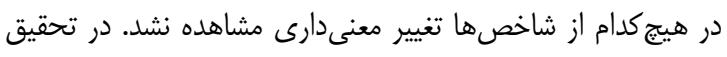

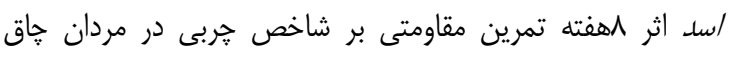

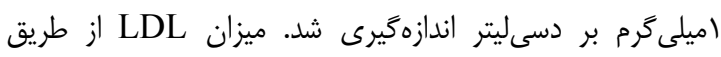

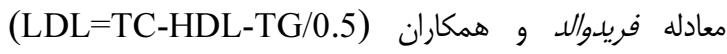

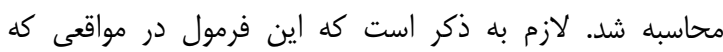

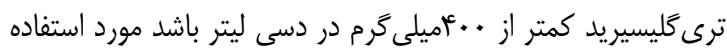

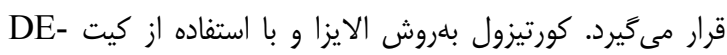
Human Wiesbadwn) SIV2930

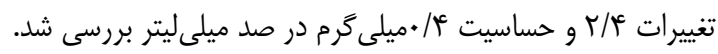

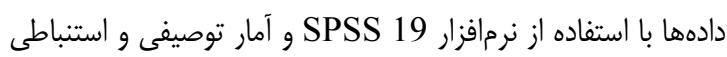

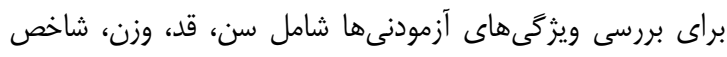

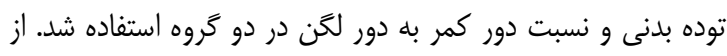

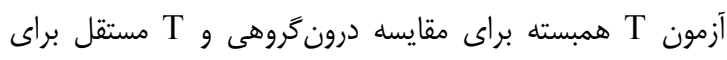
مقايسه بين گروهى استفاده شد.

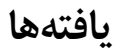

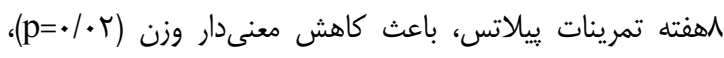

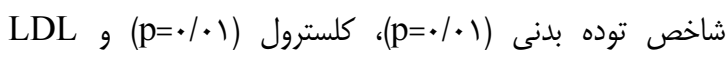
(p=./1)

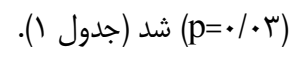

جدول () مقايسه ييش آزمون و يس آزمون در دو كَروه با آزمون T همبسته

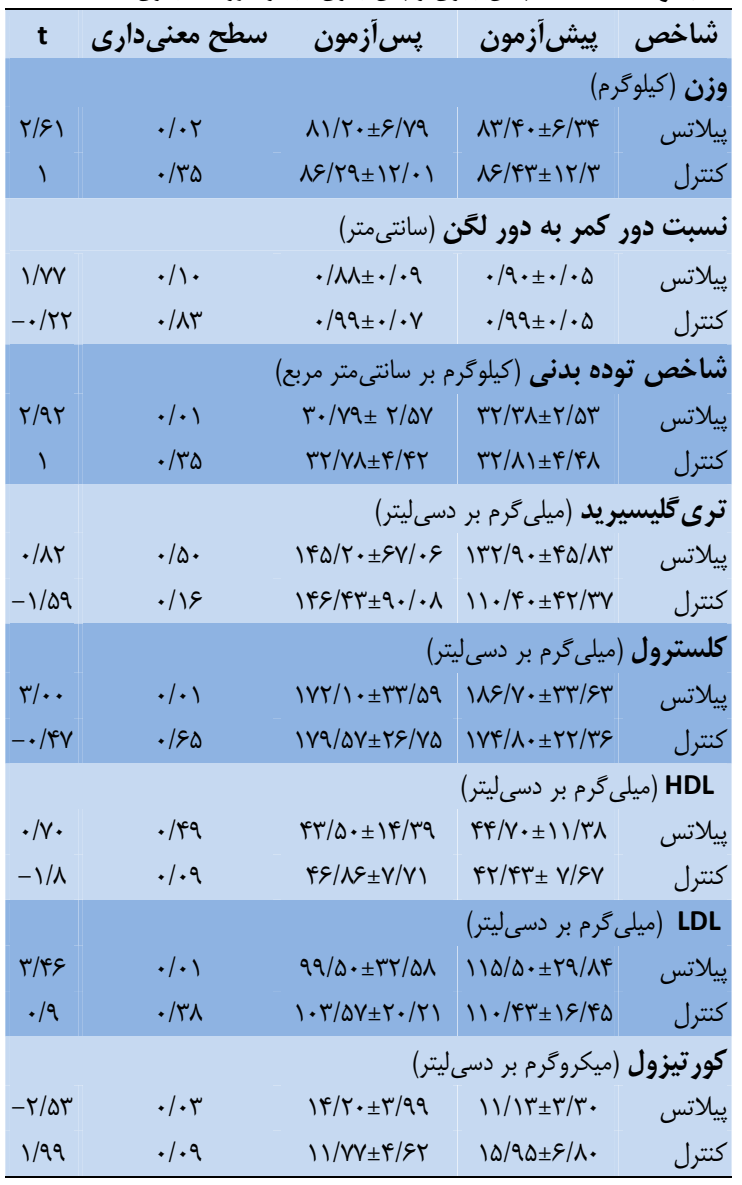




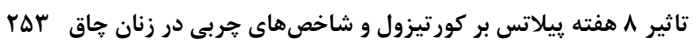

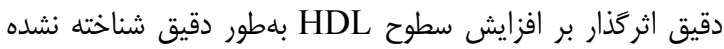

كورتيزول در گروه ييلاتس افزايش معنىدارى يافت. •.اهفته تمرينات موازى، قدرتى و استقامتى باعث افزايش معنى معنى دارد

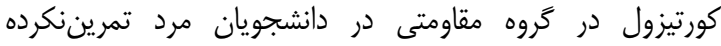

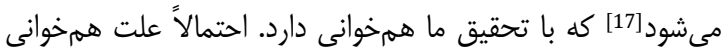

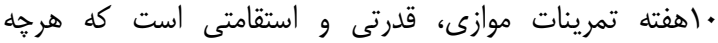

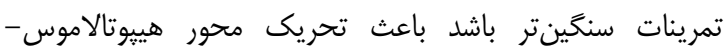
هيبيوفيز - آدرنال و افزايش ACTH و افزايش كورتيزول مىشود. rهفته تمرين مقاومتى سنخَين باعث افزايش معنى دار غلظت ترشح

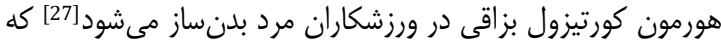

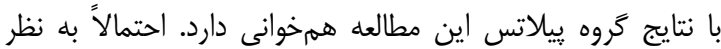
مىرسد دليل افزايش غلظت كورتيزول در شرايط استرسى و فشارهاى جسمانى تغيير در نحوه عملكرد محور هييوتالاموس-

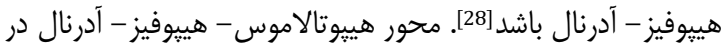
قياسخ به تمرينات سنكين و شرايط براسترس تحريك شده و ميزان

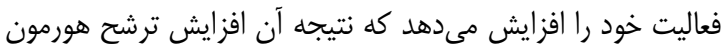
ACTH و به دنبال آن افزايش ترشح كورتيزول است [30, تغييرات كورتيزول سرم به نوع، شدت و مدت فعاليت بستخكى دارد،

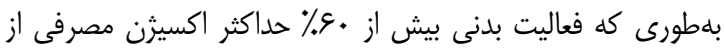
مهرمترين محركهاى ترشح اين هورمون است. فعاليت جسمانى شديد موجب افزايش ترشح ACTH و در نتيجه افزايش كورتيزول

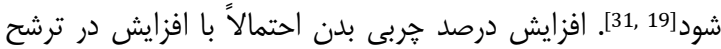

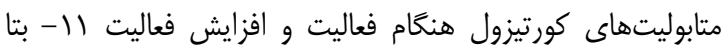
هيدروكسىاستروئيد دهيدروزناز نوع اول در بافت آديبيوز همراه

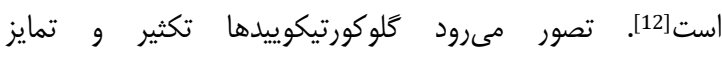
آديبوستهاى انسانى را بالا مىبرند و گيرندههاى آنها در بافت آدييوز احشايى نسبت به بافت آديبوز زيريوستى فراوانتر الانت هستند. اين موضوع نشان مىدهد كه توزيع جربى شكمى و فعاليت محور

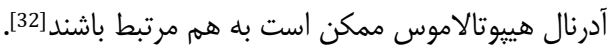
اين تحقيق اولين بار در ايران انجام شده است. در اين تحقيق،

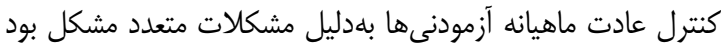

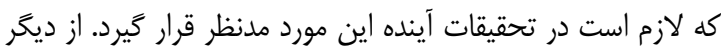

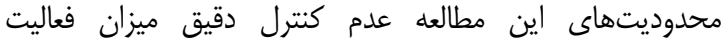

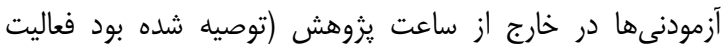

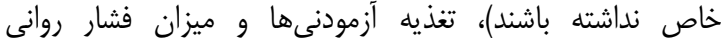

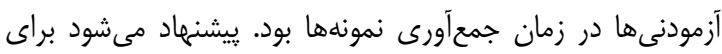

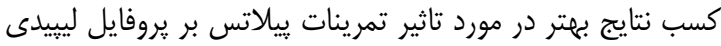

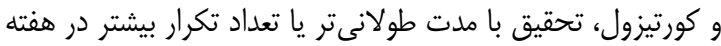

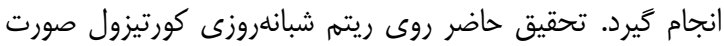

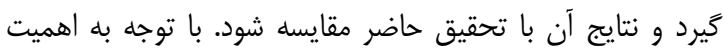

مورد بررسى قرار كرفته است كه لهذفته فعاليت ورزشى منظه، باعث كاهش معنىدار كلسترول و LDL مى شود و تغييرى بر ساير في

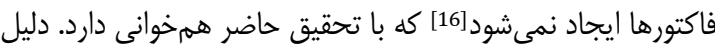

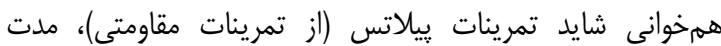

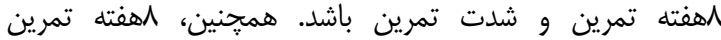

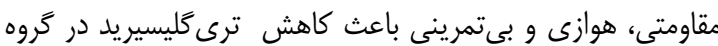

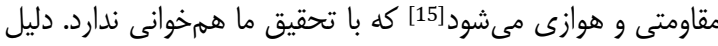

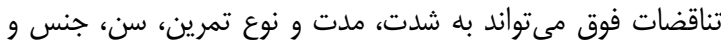

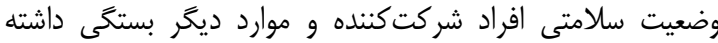
باشد. در تحقيق رمضانخانى تمرين هوازى و يِيلاتس و رزيم كم كالرى

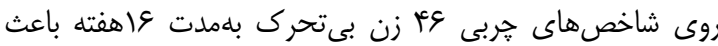

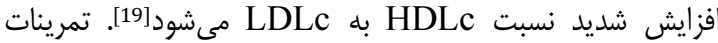
هوازى مىتواند يكى ازعلل مهرم كاهش سطوح كلسترول خون

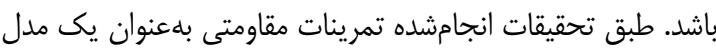

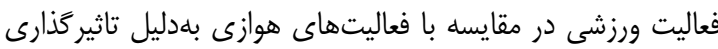

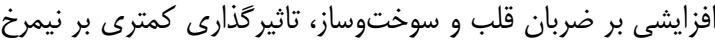

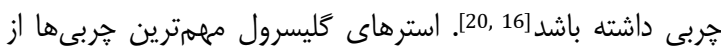
نظر كمى هستند نمونهاى از آنها ترى آسيل كليسرول (ترى كليسيريد)

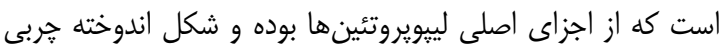

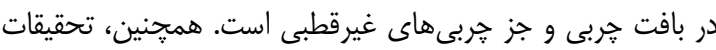

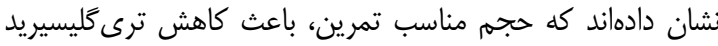

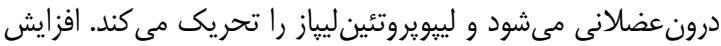

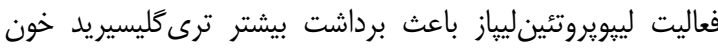

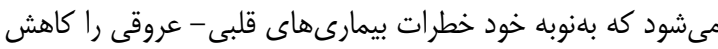

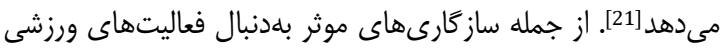
افزايش حجم ميتوكندرى و به دنبال آن فعاليت آنزيههاى لييوليز

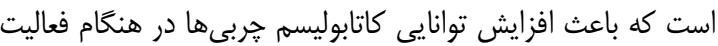
ورزشى مىشود[22]. در زنان، هنكام فعاليت ورزشى، ترشح هورمون

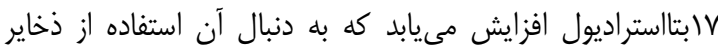

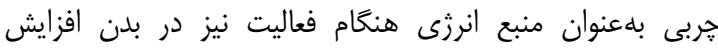

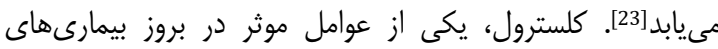

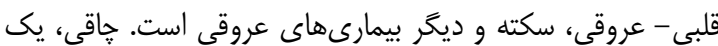

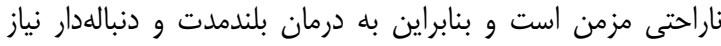

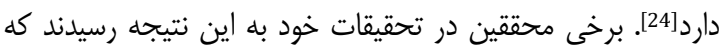
شدت تمرين مىتواند برافزايش سطوح HDL تاثيركذار باشد.

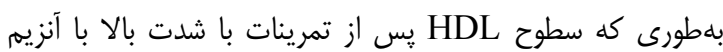
لييويروتئين ليياز (LPL) رابطه مستقيم دارد، زيرا LPL آنزيمى كليدى در كاتابوليسم ترى كليسيريد است]

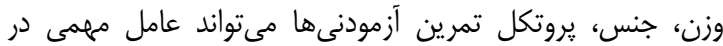

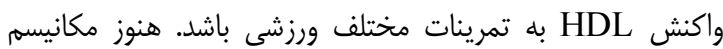


12- Azizi M. The effect of exercise on cortisol responses and energy expenditure in obese and lean men. Sport Biosici. 2009;(1):57-73. [Persian]

13- Cakmakci E. The effect of 10 week pilates mat exercise program on weight loss and body composition for overweight Turkish women. World Appl Sci J. 2012;9(3):431-8.

14- Park SB, Blumenthal JA, Lee SY, Georgiades A. Association of cortisol and the metabolic syndrome in Korean men and women. J Korean Med Sci. 2011;26(7):914-8.

15- Hosseini Kakhk S, Amiri Parsa T, Azarnive M, Hamedinia M. The effect of resistance training, aerobic training and detraining on the lipid profile and CRP in obese girls. Q J Sabzevar Univ Med Sci. 2011;18(3):188-97. [Persian]

16- Boa BC, Maria das Graças CS, Leite RD, da Silva SV, Barja-Fidalgo TC, Kraemer-Aguiar LG, Bouskela E. Chronic Aerobic Exercise Associated to Dietary Modification Improve Endothelial Function and eNOS Expression in High Fat Fed Hamsters. PloS One. 2014;9(7):e102554.

17- Gorzi A, Rajabi H, Azad A, Molanouri Shamsi M, Hedayati M. Effect of Concurrent, Strength and Endurance Training on Hormones, Lipids and Inflammatory Characteristics of Untrained Men. Iran J Endocrinol Metabol. 2012;13(6):614-20. [Persian]

18- Jago R, Jonker ML, Missaghian M, Baranowski T. Effect of 4 weeks of Pilates on the body composition of young girls.Preventive Medicine. Prev Med. 2006;42(3):177-80.

19- Ramezankhany A, Nazar Ali P, Hedayati M. Comparing effects of aerobics, pilates exercises and low calorie diet on leptin levels and lipid profiles in sedentary women. Iran J Basic Med Sci. 2011;14(3):256-63. [Persian]

20- Arazi H, Jorbonian A, Asghari E. Comparison of concurrent (resistance-aerobic) and aerobic training on VO2max lipid profile, blood glucose and blood pressure in middle-aged men at risk for cardiovascular disease. J Shahid Sadooghi Univ Med Sci. 2013;20(5):627-38. [Persian]

21- Narayani R. Effect of Aerobic Training on Percentage of Body Fat, Total Cholesterol and HDL-C among Obese Women. World J Sport Sci. 2010;3;(1):33-6.

22- Christiansen JJ, Djurhuus CB, Gravholt CH, Iversen P, Christiansen JS, Schmitz O, et al. Effects of cortisol on carbohydrate, lipid, and protein metabolism: studies of acute cortisol withdrawal in adrenocortical failure. $\mathrm{J}$ Clin Endocrinol Metab. 2007;92(9):3553-9.

23- Mirghaini J, Agha Alinejad H, Gerayli Korpi J, Alimardani A, Arshadi S, Hedayaty Katouli A. Effect of strength training on lipid profile and hormonal responses of blood testosterone and cortisol in young male Greco Roman wrestlers. Ann Biol Res. 2012;3(5):2373-7. [Persian]

24- Rahimi N, Marandi SM, Kargarfard M. The effect of eight weeks aquatic training on lipid profile of patients who suffer from type II diabete. J Isfahan Med School. 2011;29(148):988-1007. [Persian]

25- Rashidlamir A, Alizadeh A, Ebrahimiatri A, Dastani M. The effect of four-week period of aerobic exercise with cinnamon consumption on lipoprotein indicates and blood sugar in diabetic female patients (type 2). J Shahid Sadoughi Univ. 2013;20(5):605-14. [Persian]

26- Fraser $\mathrm{R}$, Ingram $\mathrm{MC}$, Anderson $\mathrm{NH}$, Morrison $\mathrm{C}$, Davies E, Connell JM. Cortisol effects on body mass, blood pressure, and cholesterol in the general population. Hypertension. 1999;33(6):1364-8.

27- Shariat A, Kargarfard M, Sharifi GhR. The effect of heavy resistance exercise on Circadian rhythm of salivary

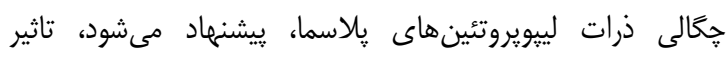

$$
\begin{aligned}
& \text { تمرينات ييلاتس بر جمالى اين ذرات بررسى شود. }
\end{aligned}
$$

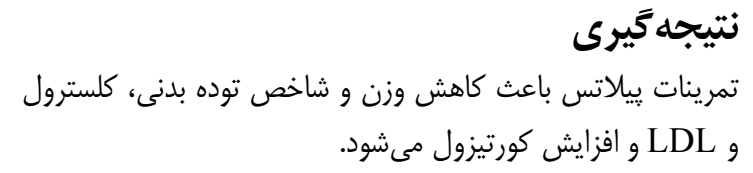$$
\text { تشكر و قدردانى: از تمامى كسانى كه در اين مطالعه ما را يارى }
$$$$
\text { نمودند قدردانى مىشود. }
$$$$
\text { تعارض منافع: موردى از طرف نويسندگان گزارش نشده است. }
$$$$
\text { تاييديه اخلاقى: موردى از طرف نويسندكان گزارش مون نشده است. }
$$$$
\text { منابع مالى: بر عهده نويسنده بوده است. }
$$

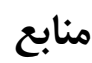

1- Alizadeh Z, Kordi R, Hossein-Zadeh M, Mansournia M. The effects of continuous and intermittent aerobic exercise on lipidprofile and fasting blood sugar in women with a body mass index more. Tehran Univ Med J. 2011;69(4):2539. [Persian]

2- Omydali Z, Taheri H, Asfrjany F, Bambaichi A, Marandi $M$. The effect of pilates training on selective physiological and physical fitness in untrained females with overweight. Biomonthly J Res Rehabil Sci. 2012;8(1):180-92. [Persian] 3- Sedaghat F, Rabiei S, Rastmanesh R. The relationship between serum cortisol and vitamin $\mathrm{C}$ levels with obesity. Jundishapur Sci Med J. 2012;11(4):341-53. [Persian]

4- Khalesi M, Gaeini A, Shabkhiz F, Samadi A, Tork F. The effect of a period of discontinuous endurance exercise on ICAM-1 and lipid profile of non-athletic male students. Q J Sabzevar Univ Med Sci. 2011;18(3):198-205. [Persian] 5- Punyadeera C, van der Merwe MT, Crowther NJ, Toman M, Schlaphoff GP, Gray IP. Ethnic differences in lipid metabolism in two groups of obese South African women. J Lipid Res. 2001;42(5):760-7.

6- Surati Jablu D, Attarzadeh Hossein R. Effects of Resistance and Endurance Exercises on Serum Androgens, Cortisol and Lactate in Menopause Women. Iran J Health Phys Act. 2012;3(1):21-9. [Persian]

7- Nasiri Rine H, Khanpoor F. Investigate The relationship between cortisol and testosterone hormones and anthropometric parameters and liver enzymes and blood glucose in men. Urmia Med J. 2012;23(5):549-55. [Persian] 8- Ravasi AA, Fallahi AA, Abbasi A. The effect of different intensities of short-term exercise on leptin, insulin, cortisol and lipid profiles in overweight and obese adolescents. Sport Biosci. 2013;(14):87-110. [Persian]

9- Segal NA, Hein J, Basford JR. The effects of Pilates training on flexibility and body composition: an observational study. Arch Phys Med Rehabil. 2004;85(12):1977-81.

10- Kaur S, Prabhnoor K, Sarvanan Sh, Manpreet KK. To compare the effect of stretching and core strengthening exercises on Primary Dysmenohrrea in Young females. J Dental Med Sci. 2014;13(6):22-32.

11- Kloubec JA. Pilates for improvement of muscle endurance, flexibility, balance, and posture. J Strength Cond Res. 2010;24(3):661-7.

دوره •r، شماره f، زمستان rari

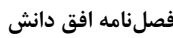




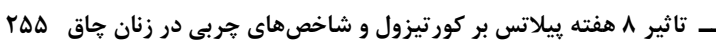

30- Praveen EP, Sahoo JP, Kulshreshtha B, Khurana ML, Gupta N, Dwivedi SN. Morning cortisol is lower in obese individuals with normal glucose tolerance. Diabetes Metab Syndr Obes. 2011;4:347-52.

31- Steptoe A, Kunz-Ebrecht, Brydon L, Wardle J. Central adiposity and cortisol responses to waking in middle-aged men and women. Int J Obesity.2004;(28):1168-73.

32- Duclos M, Marquez Pereira P, Barat P. Increased cortisol bioavailability, abdominal obesity, and the metabolic syndrome in obese women. Obes Res. 2005;13(7):1157-66. cortisol in male body building athletes. J Isfahan Med School. 2012;29(167):2400-13. [Persian]

28- Larsson CHA, Gullberg B, Råstam L, Lindblad U. Salivary cortisol differs with age and sex and shows inverseas sociations with WHR in Swedish women: A crosssectional study. BMC Endocr Disord. 2009;9:16.

29- Azizi M, Rahmani-Nia F, Mohebbi H, Azarbayjani MA. The effect of exercise on cortisol responses and energy expenditure in obese and lean men. Sport Biosci. 2009;(1):113-24. [Persian] 